\title{
Incentive System in Hungarian High Performance Sport
}

\author{
Authors' contribution: \\ A) conception and design \\ of the study \\ B) acquisition of data \\ C) analysis and \\ interpretation of data \\ D) manuscript preparation \\ E) obtaining funding
}

Tamás Sterbenz ${ }^{\mathrm{A}, \mathrm{B}, \mathrm{E}}$, Erika Gulyás ${ }^{\mathrm{A}-\mathrm{C}, \mathrm{E}}$, Lili Kassay ${ }^{\mathrm{C}, \mathrm{D}}$

Semmelweis University, Hungary

\begin{abstract}
This study will attempt to describe the role of existing incentives which have a significant effect on Hungarian sport's performance. The aim of the paper is to understand why a large gap has emerged between successful elite sports and the popular but underperforming spectacular sport. According to the concept of dual competition, in addition to sport results, the analyzed fields also concern competition for resources, particularly for the attention of supporters and sponsors. The methodology of the analysis is fundamentally economic in nature; however, qualitative methods are also given emphasis, as the analyzed topic has specific characteristics. Based on new institutional economics, the study presumes that the behavior of organizations is determined by the decisions of bounded rational individuals, and highlights the significance of the created mechanisms and institutions.
\end{abstract}

incentives, sport management, sport performance, elite sport, Hungary

\section{Introduction}

Deviating from the traditionally and voluminously analyzed sport financing, this study will instead focus on the crucial role of key motivation and performance assessment systems. In this way, it is the authors' intention to direct the attention of decision makers to the fact that the solutions worked out solely for tackling situations regarded as financing problems are not sufficient, and that only the exposure and analysis of deeper structural issues can lead to the improvement of the competitiveness of Hungarian sports.

In the approach of this study, human behavior can be understood if the form of the measurement of performance is adequately considered because the incentive systems based on performance will influence the achievements of sports as well.

* This paper is a revised and enlarged version of the winning study of a tender announced by the Hungarian Society for Sport Sciences. 
In our earlier studies (Sterbenz \& Gulyás, 2013), when examining the Hungarian basketball environment, it was shown what detrimental impacts ill-established incentive systems can have. Furthermore, it was shown that they lead to the emergence of a defective structure in sports described as a hollow pyramid.

In this study, we have relied on new methods to describe how incentive systems tend to operate with varied efficiencies in individual sports and affect the achievements of the participants.

\section{Theoretical framework}

The analysis described in this study is basically of economic nature; therefore, it assumes that the actors have rational intent. Yet in Herbert Simon's (2000) theory - due to their limited cognitive abilities and the complexity of the environment - actors make bounded rational decisions following their own interests. While trying to understand and analyze these decisions, we attribute outstanding importance to the institutional framework of the sports model.

In this economically tuned approach of sport competitions, the performance of athletes depends on their abilities and their efforts made towards achieving victory. In the conventional field of sport science (especially with reliance on the means of training theory and sport psychology), researchers demonstrate a detailed focus on influencing factors. They analyze the selection of talent, the development of training methods, and competition strategy. Nevertheless, this study employs different methods: the means of economics to examine the incentive systems of various sports, their organizational structures, environmental factors, and use the theory of tournaments (Lazaer, 1995) known from human resource management. Finally, recommendations are set forth on the basis of the analysis of data collected from Hungarian sports.

\section{Model of Hungarian elite sport}

In recent years, the volume of related literature has been growing with a focus on the identification of the factors determining elite sport achievements, as well as the exploration of correlations between Olympic successes and national endowments (De Bosscher et al., 2008). It is important to note that in several cases Hungary is seen as an exception among the examined countries, as her victories at the Olympics (Table 1) cannot be explained by the country's statistical population, economic performance, resources dedicated to competitive sports, or number of people involved in leisure time sporting activities (Bottenburg, 2002).

Table 1. Ranking on the basis of the medal tables of summer Olympic Games

\begin{tabular}{lllll}
\hline & $\mathbf{1 9 5 2}$ & $\mathbf{1 9 7 2}$ & $\mathbf{1 9 9 2}$ & $\mathbf{2 0 1 2}$ \\
$\mathbf{1}$ & USA & USSR & EUN & USA \\
$\mathbf{2}$ & URS & USA & USA & CHN \\
$\mathbf{3}$ & HUN & DDR & GER & GBR \\
$\mathbf{4}$ & & GER & CHN & RUS \\
$\mathbf{5}$ & & JPN & CUB & KOR \\
$\mathbf{6}$ & & AUS & ESP & GER \\
$\mathbf{7}$ & & POL & KOR & FRA \\
$\mathbf{8}$ & & HUN & HUN & ITA \\
$\mathbf{9}$ & & & & HUN \\
\hline
\end{tabular}

Source: own edition; www.olympic.org 
As so far it has been primarily foreign authors who have looked at Hungary's special situation (Andreff, 1996), this study also intends to bridge this gap in the related literature by using empiric analysis and modeling that relies on the authors' experience in Hungarian sports.

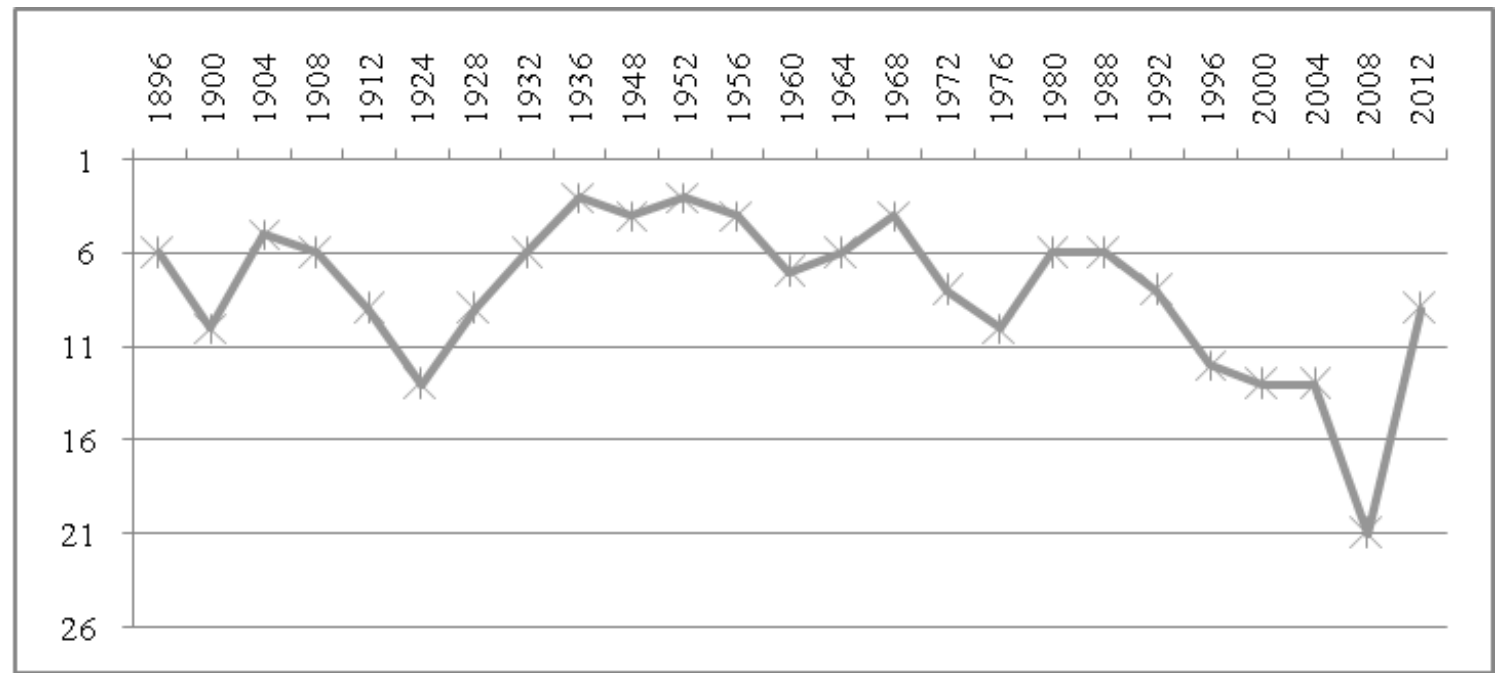

Figure 1. Ranking of Hungary on the medal tables of summer Olympic Games

Source: own edition; www.olympic.org

In the history of summer Olympic Games, Hungary has nearly always found her place among the top 10 in the medal tables (Figure 1). Therefore, it seems to be an interesting question for analysis why certain types of sports (Table 2) can show traditionally excellent performance, while other sports - also regarded as successful sports earlier - have sunk in international competition? Can such factors be found that calculably influence the individual types of sports, and explain successful performance even under the given circumstances of sharpening competition?

Table 2. Ranking of Hungarian sports in view of the number of summer Olympic medals

(1896-2012)

\begin{tabular}{lllll}
\hline & gold & silver & bronze & total \\
fencing & 35 & 22 & 26 & 83 \\
swimming & 25 & 23 & 18 & 66 \\
canoe and kayak & 22 & 29 & 26 & 77 \\
wrestling & 19 & 16 & 19 & 54 \\
gymnastics & 15 & 11 & 14 & 40 \\
athletics & 10 & 12 & 17 & 39 \\
boxing & 10 & 2 & 8 & 20 \\
pentathlon & 9 & 8 & 5 & 22 \\
water polo & 9 & 3 & 3 & 15 \\
shooting & 7 & 3 & 7 & 17 \\
football & 3 & 1 & 1 & 5 \\
weightlifting & 2 & 9 & 9 & 20 \\
judo & 1 & 3 & 5 & 9
\end{tabular}




\begin{tabular}{lllll}
\hline handball & 0 & 1 & 2 & 3 \\
rowing & 0 & 1 & 2 & 3 \\
equestrian & 0 & 0 & 1 & 1 \\
tennis & 0 & 0 & 1 & 1 \\
sailing & 0 & 0 & 1 & 1 \\
\hline
\end{tabular}

Source: own edition; www.olympic.org

In addition to our Olympic successes, we wanted to reveal the reasons for the decline of global team sports, as we think that the continuous decline after the golden age of the 1950s cannot be simply explained solely by the sharpening competition and funding problems.

The most dramatic setback occurred in what are probably the two most popular team sports in the world. In the mid 1950s, Hungarian football and basketball were among the best in Europe and the world. Yet now, and for decades, the Hungarian teams of both sports have been unable to qualify for participation in the international tournaments, the European championships and world championships, or world cups in spite of the gradually increasing number of competing teams.

Obviously, this failure can partially be the result of sharpening competition due to the operation of the international market (in team sports, Hungary proves to be the most competitive in the globally less popular water polo and handball dominated by European teams). But we also think that in addition to the volume of resources, there may be coordination mechanisms that determine allocation that are applied in an inadequate manner. Thus, they considerably distort the operating models of more complex team sports.

In view of the situation of Olympic success sports and global team sports, the model shown in Figure 2 can be drawn.

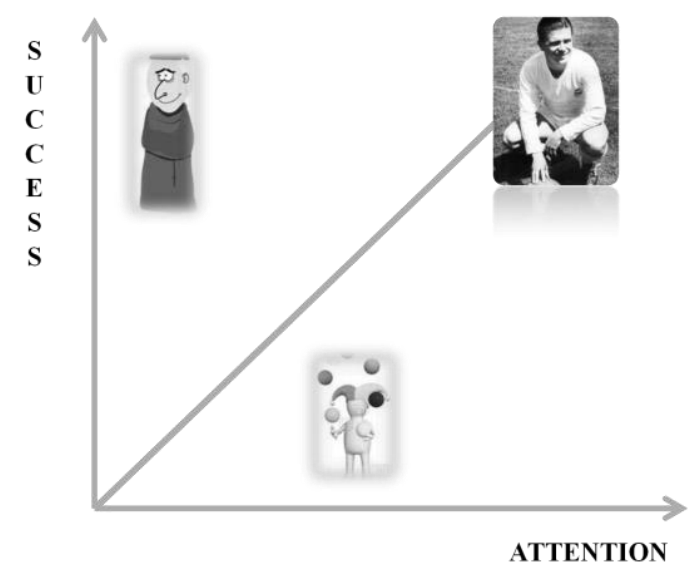

Figure 2. Model of Hungarian elite sports (Sterbenz \& Gulyás, 2013)

The international successes of Hungarian sport bring rather periodic attention to it, and because of the scheme of competition, the attention only focuses on global tournaments. In the time between one competition to the next, our athletes prepare for the main contests as "hermits," far from the interest of the global and national media. As the athletes are rarely in the limelight, market resources and funding can be attracted to the respective sports only to a limited extent. There is no close correlation between the functioning of these sports and social processes. The actual Hungarian conditions and the preparation, achievements of the athletes are not linked to each other (Laki, 2011). 
In the case of team sports continuously drawing the attention of supporters and sponsors (principally football and basketball), the established Hungarian model - with the dominance of the domestic league (the so-called NB1 championships) - solely satisfies local demands. Besides football, the functioning of basketball suggests that this model implements the "trouper" type, i.e., standards that lag far behind worldclass sports. On the local level, interesting matches can be staged with an imported workforce (international players), while Hungarian athletes result in mediocre performance. In the case of the more successful team sports (handball, water polo, ice hockey), the signs of better performance can be seen in the strengthening regional and continental club competitions, as well as the effective and winning performance of the national teams.

Regarding the domestic performance of professional sports teams, it is especially hazardous that they are traditionally funded with the involvement of communal resources (the practical risks are explained in detail in the following section of the study relating to the use of corporate income tax). In this model, the soft budgetary constraints described by Kornai (1984) prevent the emergence of proper selection needed for success in competition. The distorting effects of such soft budgetary constraints are difficult to measure in Soviet-type economies (similarly to team sports), and have had a destructive impact in the field of complex activities (Eggertsson, 1990, p. 334).

The situation of Hungarian sports is well reflected in the fact that probably it was Ferenc Puskás' performance that last achieved a shift between the two dimensions, and simultaneously attained (obviously in association with each other) world-class performance and global recognition. The risks of the established model are also indicated by the fact that the efficiency of the communal resources dedicated to raising the popularity is fairly poor. Achievements not attracting any attention from the global media strengthen the "nation of sport" image of the country only within the national borders, and have a weak influence on the improvement of leisure time sports. In association with the rational utilization of communal resources, it would be another interesting direction of research to investigate its correlation with the political and quadrennial Olympic cycles.

\section{Rationality of sport competitions}

Our study has already noted that in our economic approach athletes and professionals are deemed to be bounded rational individuals who respond to the incentives determining their usefulness with respect to their cognitive abilities and the complexity of their environment (Simon, 2000). To understand sport competition, it is important to take the fact into account that in addition to individual behavior, financial and intangible incentives influence the allocation of resources: indirectly, the structure of each sport discipline; largely, the successfulness via the expected level of performances (Sterbenz \& Gulyás, 2013).

The organizers of sport tournaments are to stage competitions that are both encouraging for the participants and entertaining for the viewers. From an economic perspective, Tullock (1960) pointed out that the maximization of the efforts of athletes who tend to maximize the expected prize is best promoted by competitions featuring the "winner takes all" model (Szymanski, 2009). Rational calculations by competitors would compare the marginal profit (prize to be won) with the marginal costs (invested work, i.e., costs of the alternative to training). This calculation depends on the weight of the efforts assumed to be made by the opponents. In game theory, the so-called Nash equilibrium (Gintis, 2009) emerges when the efforts of others are correctly estimated. In the theoretically arising state of the Nash equilibrium, each contestant would make the same amount of effort towards achievement, while the amount of rational efforts increases with higher stakes or better prizes. The "offered" efforts depend on the technology (in terms of economics, the elements of training, and the contents of training), the complexity, and uncertainties of the competitions analyzed in this study. 


\section{Role of noise in sports}

Key factors of sport performance are the endeavors and efforts made by athletes in the hope of success during preparation and at the competition. The types of movements characteristic of individual sports, as well as their rules and competition schemes, determine to various degrees the interrelation between effort and result; however, to a certain extent factors beyond the control of athletes, i.e., the noise, will always influence efficiency.

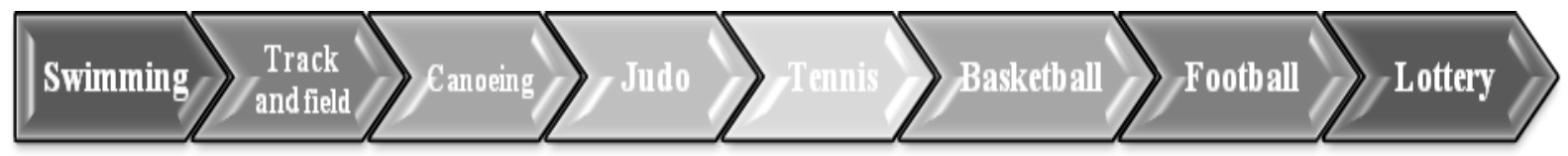

Figure 3. Noise scale

Source: own edition

The scale shows sports scattered from the least noisy (swimming) to the most complex and most uncertain type of the sports we have examined (football) with respect to the increasing extent of uncertainty and complexity. Uncertainty and complexity may arise from technical implementation or subjective judgment (score-based sports), the role of nature (for instance, weather conditions), the type of contact with the opponent, and cooperation and rivalry on the team. Influencing sport performance, uncertainty and complexity affect the behavior of the sporting participants. Only the incentive systems that take them into account would offer effective means in the sharp competition for sport achievements and the attention of supporters.

\section{Relative nature of performance in sports}

In sport competition, performance can be interpreted in relation to opponents. Naturally, sports that are measurable by objective means can also be compared to the performance of athletes being elsewhere in terms of space and time, or to the earlier performance of the same athletes. Yet the essence of competing still remains delivering better performance than the opponents under the given circumstances (Sterbenz \& Géczi, 2012).

In view of improving performance, it is especially important that in the case of sports deemed to be relative due to the associated set of rules (martial arts and team sports in the right side of the noise scale) development can be realized in two distinct ways: instead of the improvement of own performance, the deterioration of the level of the opponent can prove to be an equally rational strategy. In this context, the structure of competitive systems can largely affect the motivation of athletes, because the efforts of rational athletes need to surpass the input of the potential opponents. In the case of relative sports (especially team sports), the role of collusion should also be mentioned specifically, because by cooperating with the opponents (even implicitly) rational actors can moderate their own efforts without prejudicing their chances at a given competition. A form of collusion within the team can be the "social loaf" during preparation before the competition (Miller, 2002), which may diminish the performance of the given actors or the entire sport, especially due to its long-term effects.

\section{Tournament theory}

In economic literature, the concept known as tournament theory focuses on the relativity of performance within companies on the basis of the example of sport competition (Lazaer, 1995). Originally analyzing the structure of tennis tournaments, this theory offers the following substantial observations to our studies:

1. Noise impacts the amount of effort; the noisier an activity is, the larger disproportion in incomes is needed for rational motivation; 
2. The incomes of the actors on the top of the hierarchy influence the efforts of those in the lower ranks;

3. In the case of relative performance and a larger number of participants, collusion compromising competition impairs incentives;

4. The effectiveness of asymmetric incentive systems is better.

SYMMETRIC

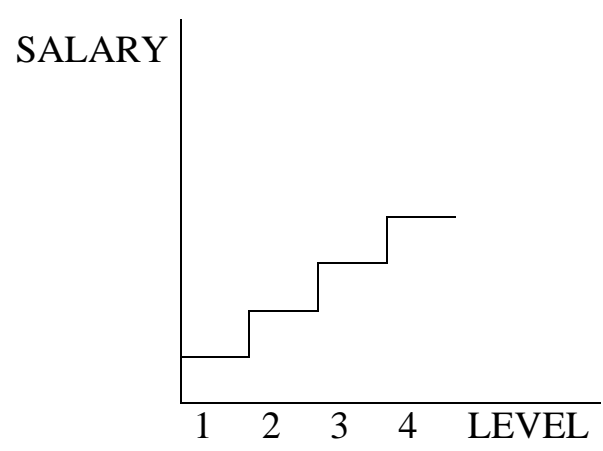

ASYMMETRIC

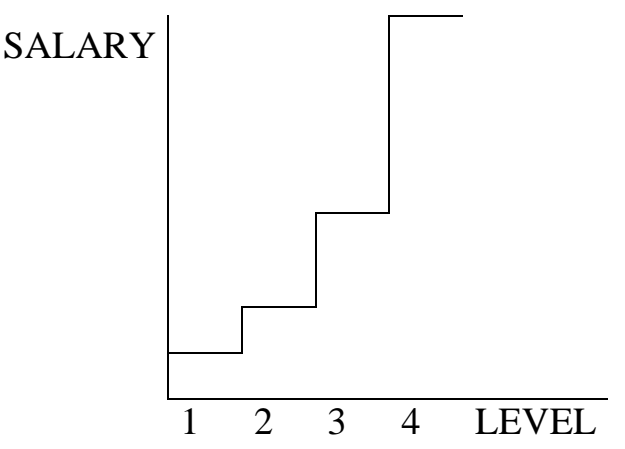

Figure 4. Two income structures

Source: Lazar (1995).

According to the economic logic of the tournament theory, when incomes are evenly distributed, the chance to emerge from the lower ranks precisely corresponds to the extra income that can be acquired with such progress, meaning that the expected value of the rationally handled game (the product of the chance and expected income) is exactly a (Figure 4). The elimination structure of tennis competitions (50\% chance) and the amount of the prize money doubled after each round reflect this rational approach (Table 3).

Table 3. US Open 2013 prizes for the individual events

\begin{tabular}{ll}
\hline Round & $\begin{array}{l}\text { Amount to be won } \\
\text { (The amounts are in USD) }\end{array}$ \\
Winner & $2,600,000$ \\
Runner-up & $1,300,000$ \\
Semi-final & 650,000 \\
Quarter final & 325,000 \\
Fourth round & 165,000 \\
Third round & 93,000 \\
Second round & 53,000 \\
First round & 32,000 \\
\hline
\end{tabular}

Source: http://www.usopen.org/en_US/about/history/prizemoney.html

In the asymmetric income structure in the upper levels of the hierarchy, the amounts of income represent multiple values in comparison with those of the lower ranks, meaning that the expected value of the game is greater than one. In this structure, strong competition arises for the acquisition of the available 
additional incomes, because in comparison with the number of competitors the prize indicates a rationally larger chance.

We think that the incentive systems developed in various sports feature differing levels of effectiveness. In the case of internationally successful Hungarian sports, one can see greater degrees of motivation compared to less successful sports. It is important to note that because of the given economic approach, effectiveness is not associated with equity; moreover, an effective incentive system can be a very inequitable means of recognition depending on the value judgment of the public.

Defined in our assumption, the incentive has been assessed only in a manner interpreted with economics, i.e., with respect to the chance to obtain financial benefits by competing in sports. In the course of analyzing the data, we compared the incentive systems established in Hungary for six specific sports. On the basis of their structure, we have tried to reveal the rationalities underlying the achievements, and point out the structural flaws of sports bringing about poorer results. The selection of the disciplines was based on the two key factors: success and attendance. Three were chosen from the most successful elite sports (swimming, kayaking, and wrestling) and three from the most popular team sports (football, basketball, and handball). Four experts of each selected sports (professionals of the national associations, federations, experts of the Semmelweis University Faculty of Physical Education and Sport Sciences) have been involved in questionnaire-based surveys and personal interviews to rank Hungarian athletes in five categories. Their numbers and the income proportions of the individual categories have been estimated on the basis of the associated data of the national federations. The five categories specified in the questionnaire:

1. World class,

2. Internationally top-ranking,

3. Domestic top-ranking,

4. Domestic league 1,

5. Domestic league 2.

From among the selected sports, the most silent sport was found to be swimming, whereas football has been identified as the noisiest sport, and we have tried to represent the various phases of the noise scale. The experts estimated the number of athletes in the given sport, as well as the associated income proportions. These have been used for the calculation of the rationality of the game for the evenly distributed and asymmetric model. On the basis of the tournament theory, expected values over 1.0 make efforts rational on the specific levels, while values under 1.0 indicate that the benefits anticipated to be obtained from additional efforts carry larger risks than gainable benefits.

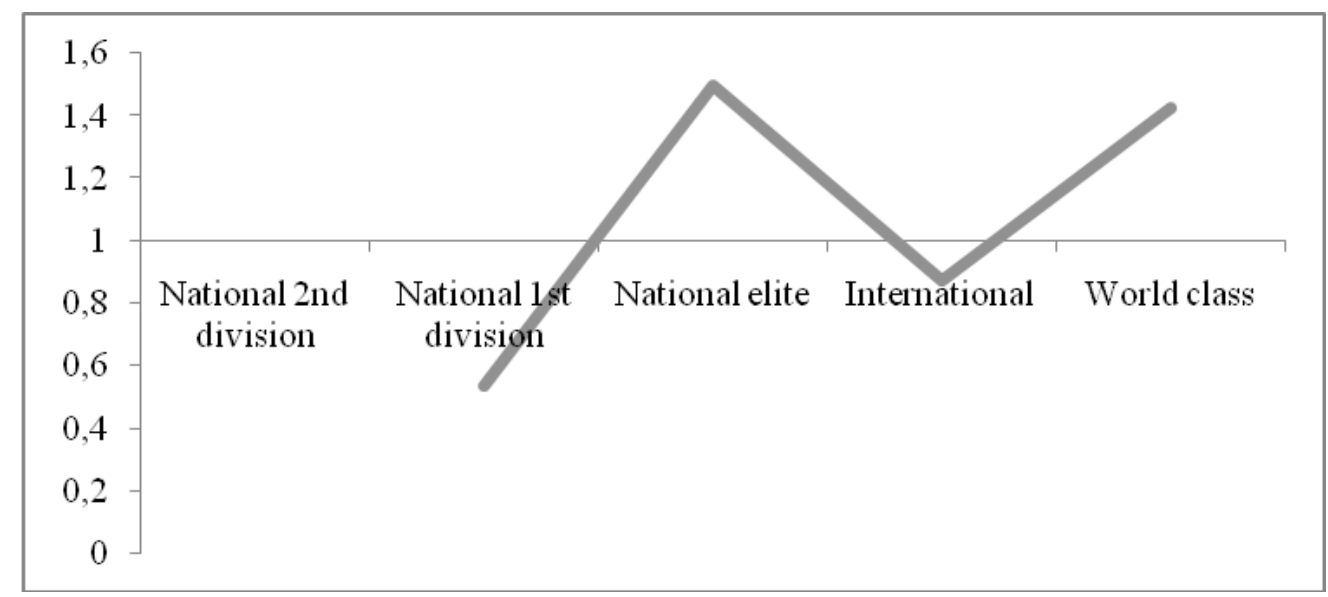

Figure 5. Expected value in swimming depending on the number of athletes and the amounts of earnings Source: own edition. 
In the case of swimming, regarded as a "silent" sport (Figure 5), data analysis shows that promotion from the domestic league 1 to the top ranks, or from the international level to the world class category, is supported by the existing incentive system. In the career of an athlete, it means that it is worth giving additional efforts to reach the domestic top ranks and the world-class category, as the given chance for the gainable income makes further work rational. With respect to the success of the sport, it is to be specifically noted that the outstanding expected value of the world-class category means strong motivation for athletes currently at the international level of performance, and encourages athletes having made significant achievements so far to give further effort.

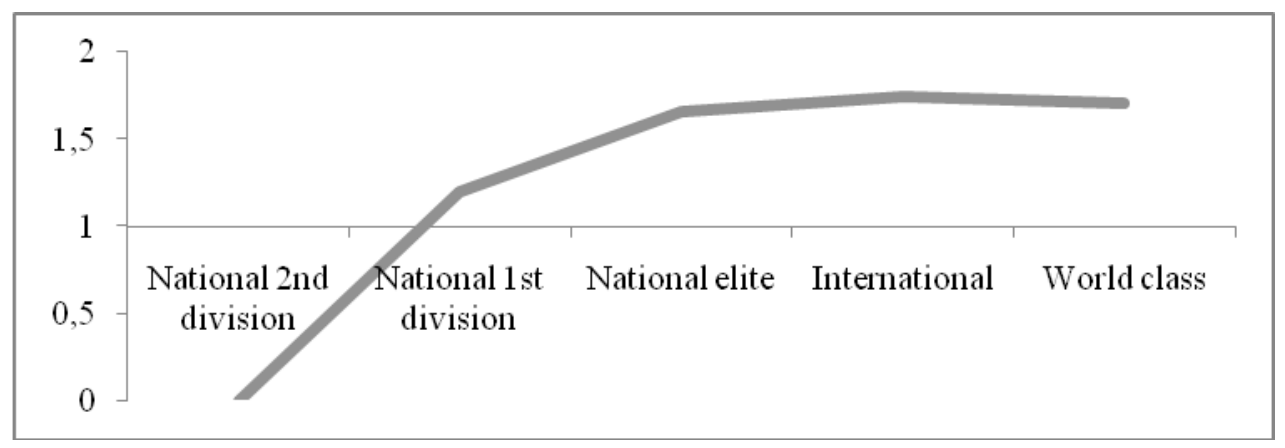

Figure 6. Expected value in canoe and kayak depending on the number of athletes and the amounts of earnings Source: own edition.

Among the selected sports, the most even, strong incentive is present in canoe and kayak (Figure 6). In the light of the received data, whoever enters the world of competition will experience a continuous and steadily strong motivation system. The relatively small numbers of athletes who are willing to shoulder the demands of the international scene in this sport are prompted to make great efforts.

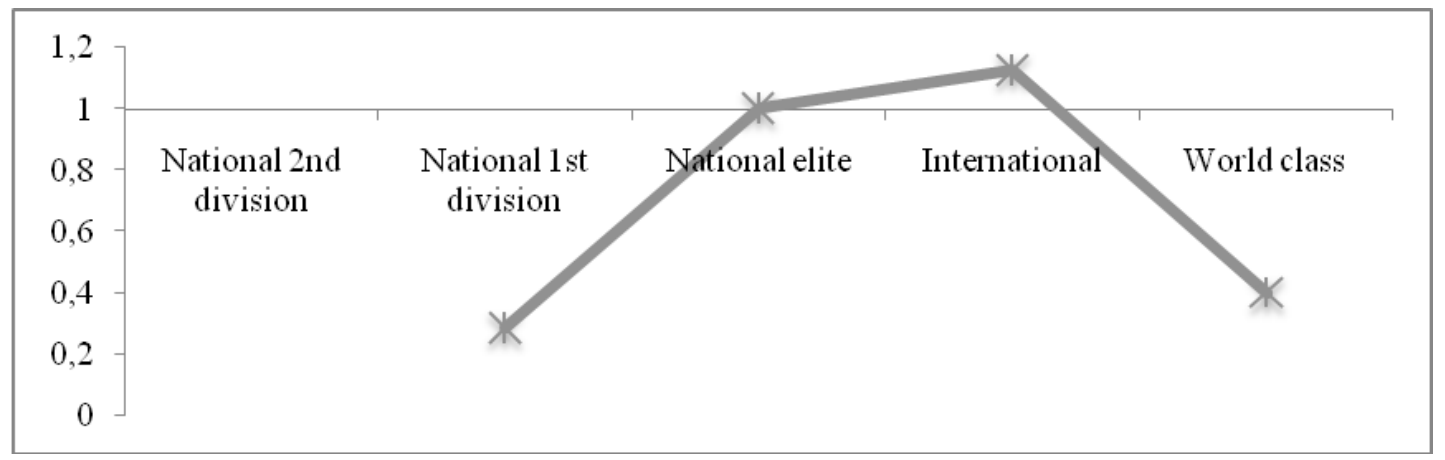

Figure 7. Expected value in handball, as depending on the number of athletes and the amounts of earnings

Source: own edition.

In handball (Figure 7), the expected value reflects strong motivation when there is the chance to become promoted from the domestic top ranks, meaning that rational calculation supports additional efforts needed for reaching the international level (national team members). The low value of entering the worldclass category indicates that access to this select group is not induced by the asymmetric income structure, i.e., motivation that is present in the structure of this sport does not foster the realization of this last, obviously most difficult step. 


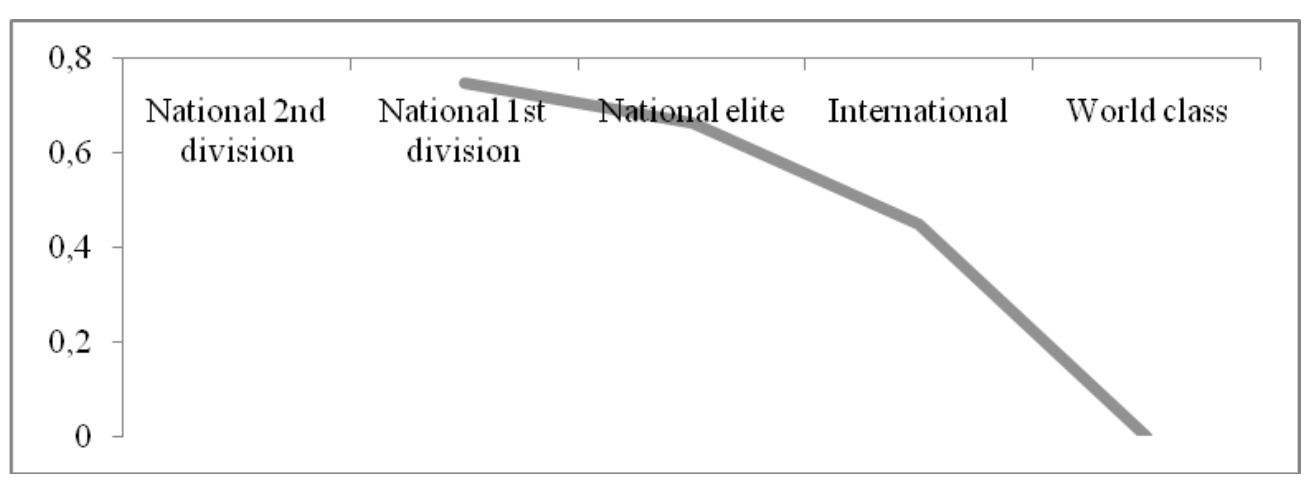

Figure 8. Expected value in basketball depending on the number of athletes and the amounts of earnings

Source: own edition.

The data received in relation to basketball (Figure 8) consistently show values less than 1.0, which is exceptional among the selected sports. This tendency indicates that for rational athletes the effort needed to rise to the upper categories is not proportionate to the anticipated benefits. The obtained results reinforce the existence of the situation described as the "hollow pyramid" (Sterbenz \& Gulypr, 2013), and indicate the flat, broadened shape of the Hungarian structure of this sport. The gradually increasing number of teams in League NB 1 and NB 1/B has widened the income potential for the athletes. The number of professional athletes has risen to a level where it has weakened the motivation required for further development.

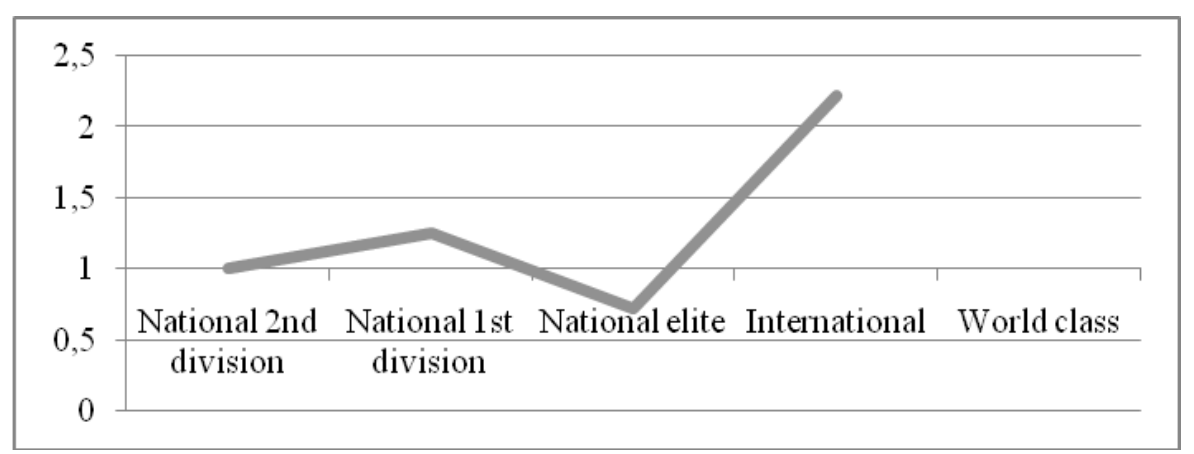

Figure 9. Expected value in football depending on the number of athletes and the amounts of earnings

Source: own edition.

The expected values calculated for football (Figure 9) exceed the value 1.0, which indicates a rational and neutral position against risks in the case of the domestic top ranks, but owing to the "noisy" nature of the sport it does not seem to be sufficient motivation. In view of its success and the structure of the sport, the Hungarian model of football is similar to the "hollow pyramid" phenomenon also seen in basketball. It is especially notable for basketball and football that they do not show a trace of the asymmetry arising from the highest level of noise, but in Hungary these sports instead feature flat structures rewarding mediocre performances.

\section{Conclusion}

The study - with reliance on actual examples from the sports concerned - has presented an overview on the theoretical correlations of motivation and performance in competitive sports. The analysis has demonstrated that the structures of sports and competition systems influence the behavior of the participants; therefore, a systematic, strategic attitude is required for the improvement of international competitiveness. 
When summarizing the investigation into the role of noise, our studies have underscored that while the incentive systems of internationally successful sports are economically effective, the established structure of less successful noise team sports resulting in strong global competition does not have sufficiently strong enough motivation. In contrast to companies, incentive systems are not solely the results of managerial decisions made on hierarchical relations, but are considerably impacted by horizontal market relations (especially the labor market), and therefore are to be handled by the associated research in a complex manner, together with the structural models of the given sports.

\section{REFERENCES}

András, K. (2003). Üzleti elemek a sportban, a labdarúgás példáján /Business elements in sports, through example of football./ Unpublished PhD thesis, Budapest University of Economic Sciences and Public Administration, Budapest, Hungary.

Andreff, W. (1996). Economic environment of sport: a comparison between Western Europe and Hungary. European Journal for Sport Management (EJSM), 2(2), 23-35.

De Bosscher, V., Bingham, J., Shibli, S., Van Bottenburg, M. \& De Knop, P. (2008). The global Sporting Arms Race. An international comparative study on sports policy factors leading to international sporting success. Aachen, Germany: Meyer \& Meyer Sport.

Kornai, J. (1985). Contradictions and Dilemmas. Budapest: Corvina and Cambridge, UK: MIT Press, 1986.

Eggertsson, T. (1990). Economic behavior and institutions. Cambridge, UK: Cambridge University Press.

Akerlof, G.A. \& Shiller, R.J. (2009). Animal Spirit: How Human Psychology Drives the Economy, and Why It Matters for Global Capitalism. Princeton, USA: Princeton University Press.

Gintis, H. (2009). The Bounds of Reason: Game Theory and the Unification of the Behavioral Sciences. Princeton, USA: Princeton University Press.

Gulyás, E. (2013). Modelling the competitiveness of the Hungarian sport. In EASM Conference, September 11-15 Istanbul, Turkey.

Laki, L. (2011). Elöszó. Sport az újkapitalizmusban /Preface. Sport in new capitalism/. In T. Sterbenz \& G. Szőts (Eds.) Sportágak versenye / Competition of Sports/ (pp. 6-17). Budapest: MSTT.

Lazar, E.P. (1995). Personnel Economics. Cambridge, USA: MIT Press.

Milgrom, P. \& Roberts J. (1992). Economics, Organization and Management. Englewood Cliffs: Prentice-Hall.

Miller, G.J. (1993). Managerial Dilemmas: The Political Economy of Hierarchy. Cambridge, UK: Cambridge University Press.

Simon, A.H. (2000). Administrative Behavior: A study of decision-making processes in administrative organization. New York, USA: The Free Press.

Sterbenz, T. (2003). Sportmenedzseri döntések /Sport managerial decisions/. Vezetéstudomány, 34(6), 25.

Sterbenz ,T., Géczi, G. (Eds.) (2012). Sportmenedzsment/Sport management/. TF jegyzet, Budapest, Hungary: TF.

Sterbenz, T., Gulyás, E. (2014). Lyukas piramis /Hollowed pyramid/. Vezetéstudomány, (45)1, 24. - 30.

Sterbenz, T. \& Szőts, G. (2011). Sportágak versenye /Competition of sports/. Budapest, Hungary: MSTT.

Szymanski, S. (2009). Playbooks and Checkbooks. Oxford, UK: Oxford University Press.

AUTHOR'S ADDRESS:
Tamás Sterbenz

Semmelweis University, Hungary

Faculty of Physical Education and Sport Sciences

Department of Sport Management

Alkotás utca 44, 1123 Budapest

Hungary

E-mail: sterbenz@tf.hu 